\title{
Population Size and Habitat Utilization of Menelik's Bushbuck (Tragelaphus scriptus Meneliki Neumann, 1902) in Abasheba-Demero Controlled Hunting Area, Southeastern Ethiopia
}

\author{
Dadi Jatani ${ }^{1}$ Demeke Datiko ${ }^{2}$ Dejene Worku ${ }^{3 *}$ \\ 1.Madda Walabu University, Collage of Natural and Computational Science, Department of Environmental \\ Science, Bale- Robe, Ethiopia \\ 2.United Nations Development Program Project Officer (Enhanced Management and Enforcement of Ethiopia's \\ PA Estate Project), Addis Ababa, Ethiopia \\ 3.Madda Walabu University, Collage of Natural and Computational Science, Department of Environmental \\ Science, Bale- Robe, Ethiopia
}

\begin{abstract}
Background: Despite Ethiopia is among few African countries with high wild animal species diversity, its mammalian resource is highly degrading. Hence, assessing the demography and ecology of the wild animals is indispensable to provide information on the current status of animal, which helps for better wildlife conservation and management purpose. Thus, an investigation on the population size and habitat utilization of endemic Menelik's bushbuck (Tragelaphus scriptus Meneliki Neumann, 1902) in Abasheba-Demero controlled hunting area was done for one year during both dry and wet seasons of the year, 2019.

Objective: The objective of investigation was to gather baseline data on population size, structure and habitat utilization of Menelik's bushbuck in Abasheba- Demero CHA.

Methodology: To reach the objective, quantitative data was collected using 18 representative random sampling of line-transects covering sample area of $18 \mathrm{~km}^{2}$. For field survey, the total area of the controlled hunting area was systematically clustered into four sample units based on the major habitats of the study area (Montane forest habitat, woodland, riverine and seasonal grass-wetland) habitat.

Data Analysis: SPSS computer software version 20, descriptive statistics and chi-square test were used to analyze the data.

Result: The projected population of Menelik's bushbuck was $519.36 \pm$ individuals. From the total population, Male bushbuck covered $38.27 \%$ females were $50.62 \%$ and young's were $11.1 \%$. The sex ratio of male to female was found to be 1:1.32. Age structure was dominated by adults, which constituted $55.5 \%$ of the total population. Although, the bushbucks were evenly distributed in all the four habitat types in both seasons, its frequency was higher in the riverine forest habitat (3.33 individuals per $\mathrm{km}^{2}$ ). The most commonly observed group types throughout the study period were single (solitary) bushbuck.

Conclusion: Based on the current study result the population of Menelik's bushbuck was not in immediate danger. However, negative attitude of local people towards the CHA and anthropogenic pressures are major underlying problem that needs appropriate correction measure.
\end{abstract}

Keywords: Abasheba-Demero, Controlled hunting area, Menelik's bushbuck

DOI: $10.7176 /$ ALST/76-03

Publication date:September $30^{\text {th }} 2019$

\section{INTRODUCTION}

\subsection{Back Ground of the Study}

Protected areas are one of biodiversity protection centers and source of tourism resources for a country, like Ethiopia through providing sustainable assistance to the local community while supporting for the maintenance and rehabilitation of the protected areas themselves (Stephens et al., 2001). Wildlife in Ethiopia is protected by the Wildlife Development, Conservation and Utilization Council of Ministers Regulations No. 163/2008and other relevant legislation. These laws define categories of wildlife and provides for their protection and in some cases utilization.

The concept of animal-habitat interaction is cornerstone in effective conservation and management of wildlife populations. Hall et al. (1997) defined habitats as the resources and conditions present in an area that provides possession, including survival and reproduction of a given organism. According to Thomas (1979), the concept of habitat goes beyond vegetation or vegetation structure as it encompasses all the specific resources (biotic and abiotic) that are needed by organisms. These resources include cover, food, water, and special factors needed by a species for survival and reproductive success. Habitat preference is the consequence of habitat selection, resulting in the disproportional use of some resources over others there by contributing to the individual's fitness (Johnson, 2007). 
Menelik's bushbuck (Tragelaphus scripus Meneliki) is an African Artiodactyls of the family Bovidae antelope species found only in Ethiopia (Yalden et al., 1984; Dereje Yazezew et al., 2011). Bushbucks are perceived to be predominantly browsers (Wronski et al., 2009) and selective concentrate feeders, that choose to eat leaves, shoots and sometimes flowers of dicotyledonous plants (Apian and Wronski, 2005), nevertheless they are able to modify their feeding habits when necessary. They feed on various species of trees, shrubs, perennial woody and annual non-woody herbs, and sometimes grass (Hofmann, 1973; Apio and Wronski, 2004; Wronski and Apio, 2006; Dereje Yazezew et al., 2011; Mignot Zerihun, 2012).

Latest genetic studies by Moodley and Bruford (2007) and Moodley et al. (2008) showed two genetically divergent lineages of Tragelaphus scriptus. Among them, one lineage inhabits the north-western half of the African continent (Tragelaphus scriptus scriptus), while the other lineage (Tragelaphus scriptus sylvaticus) (bushbuck/ Imbabala) that is found in the south-eastern half of Africa. The Tragelaphus scriptus scriptus (harnessed antelope/ kéwel) is smaller than Tragelaphus scriptus sylvaticus (Moodley et al. 2008). It shows clear stripes and patters on reddish or yellowish background with little or no sexual dimorphism in this ground colour (Moodley et al., 2008). On the other hand, Tragelaphus scriptus sylvaticus shows considerable colour variation in different habitats, especially in males (yellow to red-brown, through brown to almost black) and have striping. Moodley and Bruford (2007) and Wronski et al. (2009) suggested that ecological heterogeneity on the African mainland acted as a driving force for phenotypic diversification by promoting local adaptation.

As indicated by Yalden et al. (1984), three subspecies are believed to occur in Ethiopia. The common bushbuck (Tragelaphus scriptus decula) inhabits most of the northern parts of the country including the Simian Mountains and highlands extending to the Awash River Valley. The southern half of the country is mainly inhabited by the endemic subspecies, Menelik's bushbuck (Tragelaphus scriptus meneliki). This species is found on the highlands of Bale, Arsis, Chercher, western Shoa, Illubabor, Denkoro forest, Borena Saint National Park and Menagesha-Suba state forest at altitudes ranging between $2400 \mathrm{~m}$ and $3440 \mathrm{~m}$. The third subspecies, (Tragelaphus scriptus fasciatus), is rare and is restricted to riverine forests of the southeastern parts of Ethiopia along the Wabi Shebelle River (Yalden et al., 1984; Abebayehu Dessalagn and Tilaye Wube, 2012).

The Bale Mountains eco-region has six designated Controlled Hunting Areas (CHA) primarily for trophy hunting of mountain nyala and Menelik's bushbuck. The CHAs are cooperatively managed by the Ethiopian Wildlife Conservation Authority (EWCA), Oromia Regional government, and a licensed safari. Trophy hunting is a specific and selective legal form of wildlife use that involves payment for a hunting experience and the acquisition of a trophy by the hunter. One of the endemic wild Mammals of Ethiopian highlands from the Bovidae family is Menelik's bushbuck.

However, unlike mountain nyala this sub-specie is not well studied due to its elusive, shy and forest dwelling behavior (Kingdom, 1997). As noted by Last (1982) Menelik's bushbuck is mostly a forest living animal inhabiting dense bushes usually near water. This sub-species is a montane antelope, which is distinguished by absence of pale dorsal color, long hairs and very dark gray-brown pelage in the male.

The Convention on Biological Diversity, of which Ethiopia is a signatory, advocates that every country has the responsibility to conserve, restore and sustainable use the biological diversity within its jurisdiction. Loss of biodiversity has serious economic and social costs for any country. While following the path of development, Ethiopia has been sensitive to needs of conservation. There has been growing part of realization in society that natural resources provide base for economic and social development.

The Bale Mountain highlands of southeastern Ethiopia are unique in Africa and are known as center of endemism. They encompass Africa's largest alpine plateau and contain the largest populations of Africa's most charismatic and endemic species. The current study place, Abasheba-Demero controlled hunting area (Abasheba-Demero CHA) is one of the recently established and active CHA in Bale Zone, Goro district. Currently the area is leased to an investor whose name is Ethiopian Rift Valley Hunting Safari Privet Limited Company. As per knowledge of investigators, there were no scientific data on Population Size and Habitat use of Menelik's Bushbuck (Tragelaphus scriptus Meneliki) in Abasheba-Demero Controlled Hunting Area. Consequently, the present study has an aim for contributing to fill the stated gap. Therefore, the findings will help to improve wildlife management decisions, promote the revision of wildlife policies, initiates scientific research, help to set annual quota for trophy hunting and supplement conservation strategies of wildlife of the study site.

\subsection{Objectives}

The objectives of the study were to Estimate population size of Menelik's bushbuck in the CHA, to evaluate population structure of the animal and determine habitat utilization of Menelik's bushbuck in Abasheba- Demero CHA. 


\section{MATERIALS AND METHODS}

\subsection{Materials}

The materials that were used in the field study of this research includes: digital camera, GPS, field guide books, communication radio, data sheets, binocular, field tent and sleeping bags,.

\subsection{Description of the study area}

Goro district is one of the administrative territories in Bale zone with an area of $1,339 \mathrm{~km}^{2}$. It is geographically located between $6^{0} 29$ "- $7^{0} 15^{\prime \prime} \mathrm{N}$ latitude and $40^{\circ} 10^{\prime \prime}-40^{\circ} 45^{\prime}$ " longitude. The district has 26 kebeles \& 3 urban centers. The three urban centers are Goro town, the centers of the ditrict, Maliyu-Burka and Malka-Buta town, where three of them have their own Municipalities. Abasheba-Demero controlled hunting area (CHA) is found in the south west part of this district and to the eastern flank of the Bale Mountains National Park. This specific area has a distance of $57 \mathrm{~km}$ from Robe town and about $487 \mathrm{~km}$ from Adiss Abeba. The CHA covers an area of $210 \mathrm{~km}^{2}$ (EWCA, 2013) with elevations ranging from 1,600 to 2,600 m a.s.l. The vegetation in the study area consists of two well defined habitat types; the upper afro-montane $(2,300 \mathrm{~m}-3,200 \mathrm{~m})$ and lower afro-montane forest $(1,500 \mathrm{~m}-2300 \mathrm{~m})($ Evangelista et al.,2015). Dominant tree species include Prunus africanus, Albizuia schimperiana, and Croton macrostachyus and Scheflera Abyssinia. Each of the forested habitat types are interspersed with open areas that offer viewing opportunities (Evangelista el al., 2015).

Abasheba-Demaro CHA is managed by a private investor known as "Ethiopian Rift Valley Safaris P.L.C", the sole concession holder since its establishment in 2002. Mountain nyala and Menelik's bushbuck are the primary attraction for sport hunters, and EWCA has consistently allocated a harvest quota of five to six trophy bulls each year.

The mean annual rain fall of the district is about $750 \mathrm{~mm}-1150 \mathrm{~mm}$. There are two rain fall and cropping seasons: the main rainy season from March to May, and the short rainy season from August to November. The former contributes $55 \%$ of the total annual crop production and the latter covers areas at high and medium altitudes. The annual mean temperature ranges from $25^{\circ} \mathrm{c}$ to $30^{\circ} \mathrm{c}$ for low land areas and from $16^{\circ} \mathrm{c}$ to $20^{\circ} \mathrm{c}$ for high land area (Mekonnin, 2013). Regarding land use, from the total area cultivated land covers $64.5 \%$, under grazing covers $9 \%$.Forest covers $15 \%$. Swampy and marshy area covers $11 \%$ of the district (Goro District Agriculture Office, 2018).

\subsection{Methods}

\subsubsection{Sampling design}

Line transect sampling method was employed to survey the animal population structure, and habitat utilization. Based on the preliminary observation, the vegetation cover and topography of the area were not homogenous. Therefore, for the purpose of this investigation, following similar methods with Zerihun Girma et al, (2015), the entire study area was stratified and random sampling design applied across the four dominant habitat types found in the study area; namely Montane forest habitat, woodland, riverine and seasonal grass-wetland habitat. Bushbuck population estimation, structure and habitat utilization were examined using a representative random sampling design of line transects method (Buckland et al., 1993). Line transects survey is the method commonly used distance-based method for surveying large animals like African ungulates and livestock in preference to point transects (Sutherland, 1996; Dereje Yazezew et al., 2011).

A total of 18 transect were made on the identified four sample area. The number of transects that laid on the major habitats types were based on the total size of the habitat. The representative transects that cross each habitat were randomly selected in order to represent all of the major habitat type. Hence, ten transects with width of $0.2 \mathrm{~km}$ and $5 \mathrm{~km}$ length each $\left(10 \mathrm{~km}^{2}\right)$ were laid on the montane forest habitat, four transects with $0.2 \mathrm{~km}$ width and $4 \mathrm{~km}$ length $\left(3.2 \mathrm{~km}^{2}\right)$ on the woodland habitat, two transects with $0.6 \mathrm{~km}$ width and $3 \mathrm{~km}$ length each $\left(3.6 \mathrm{~km}^{2}\right)$ on the seasonal grass-wetland habitat and similarly two transects with $0.2 \mathrm{~km}$ width and $3 \mathrm{~km}$ length each $\left(1.2 \mathrm{~km}^{2}\right)$ were laid on the riverine habitat,

Each of the transect-line was located randomly in the study area in each of the habitat type using Garmin hand held GPS. Spaces of about 200-500 m was left between consecutive transects based on vegetation type and density to avoid double counting. All transects were laid roughly parallel to each other and the same transects was used for both wet and dry seasons survey. Each transects in a given habitat were surveyed at the same time twice per day. The transect lines were demarcated using natural boundaries like rivers, streams, rocks, big trees etc. 
The total area of the CHA was clustered in to four major habitat types;

1. Motane forest zone was the first largest habitat of the study area (Plate 2).

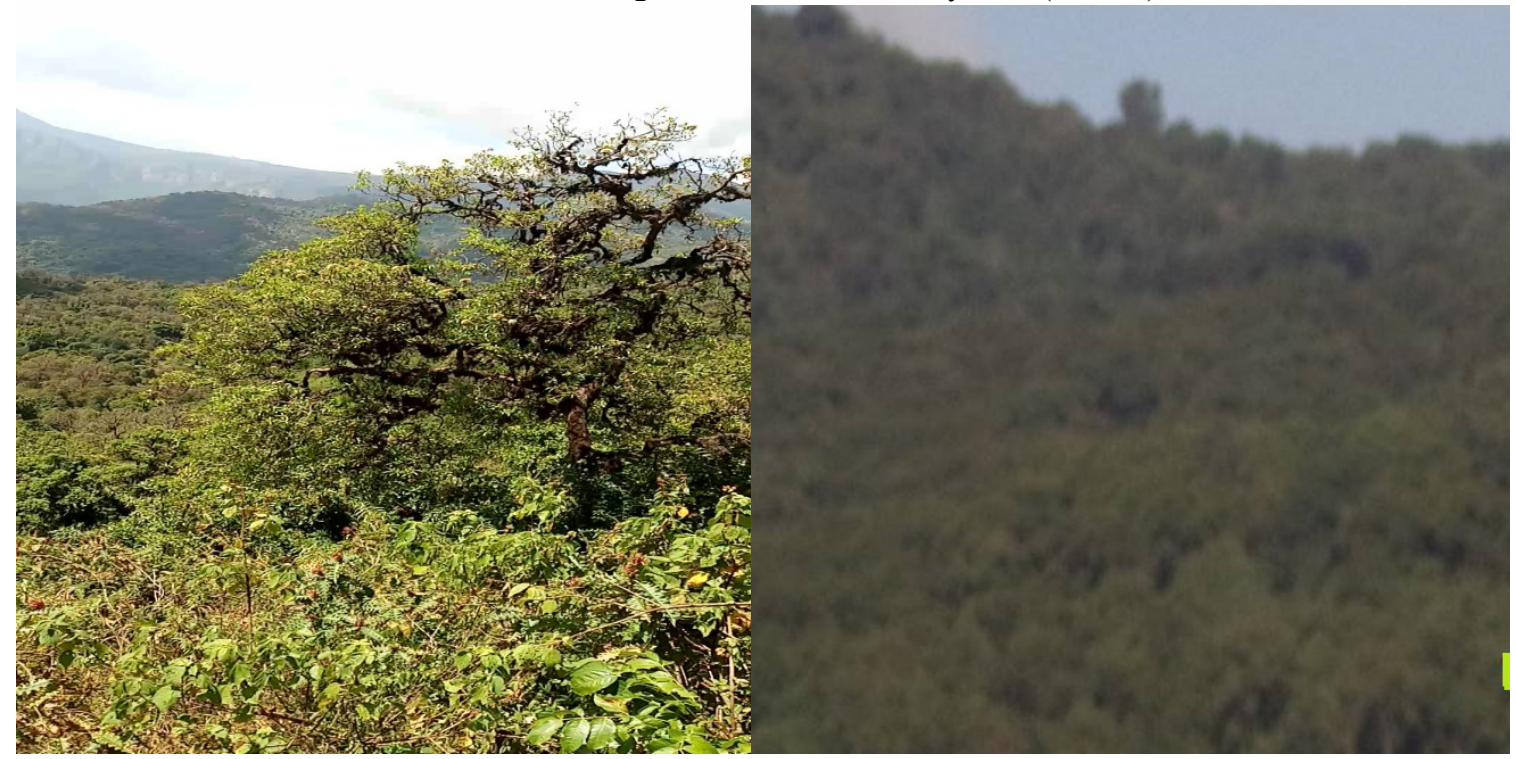

Plate 2a, Dry season

Plate $2 b$, Wet season

Plate 2: Erica habitat (2a, Dry Season; 2b, Wet Season) (photo: Dadi, 2019).

2. The wood land zone was the second largest habitat of the study area (Figure 2).

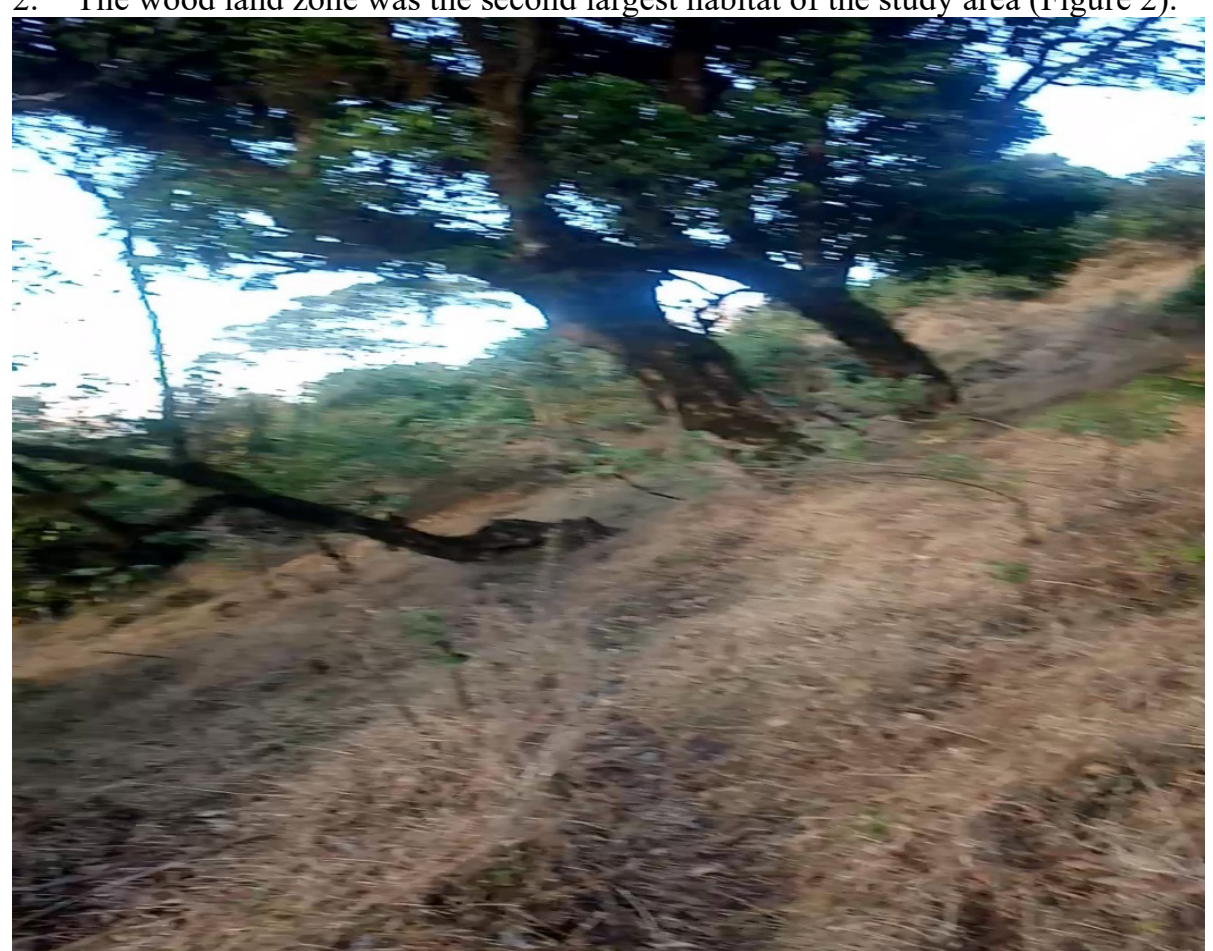

Figure 2: Woodland habitat in dry season (photo: Dadi, 2019). 
3. Reverine forest was the third largest habitat of the study area (Figure 3).

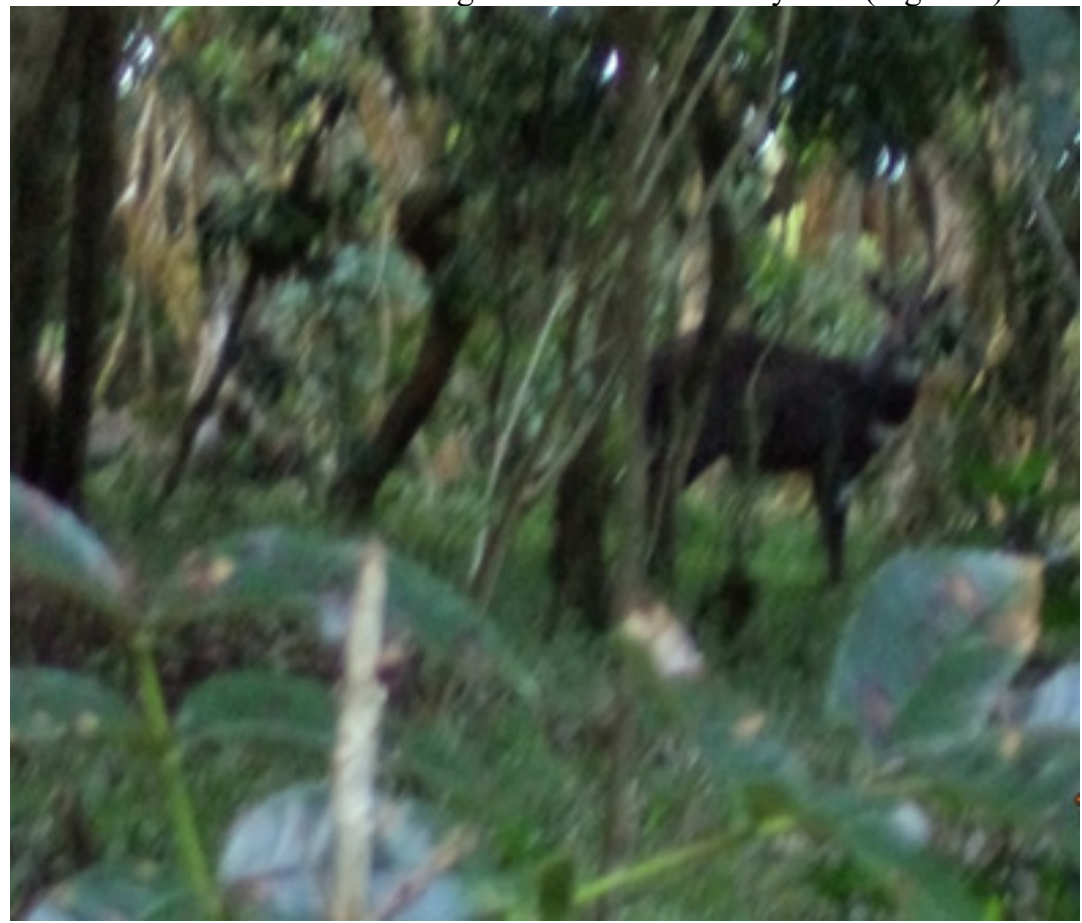

Figure 3: Riverine forest habitat in wet season (photo: Dadi, 2019).

4. Seasonal grass-wetland was smallest habitat (Plate 3).

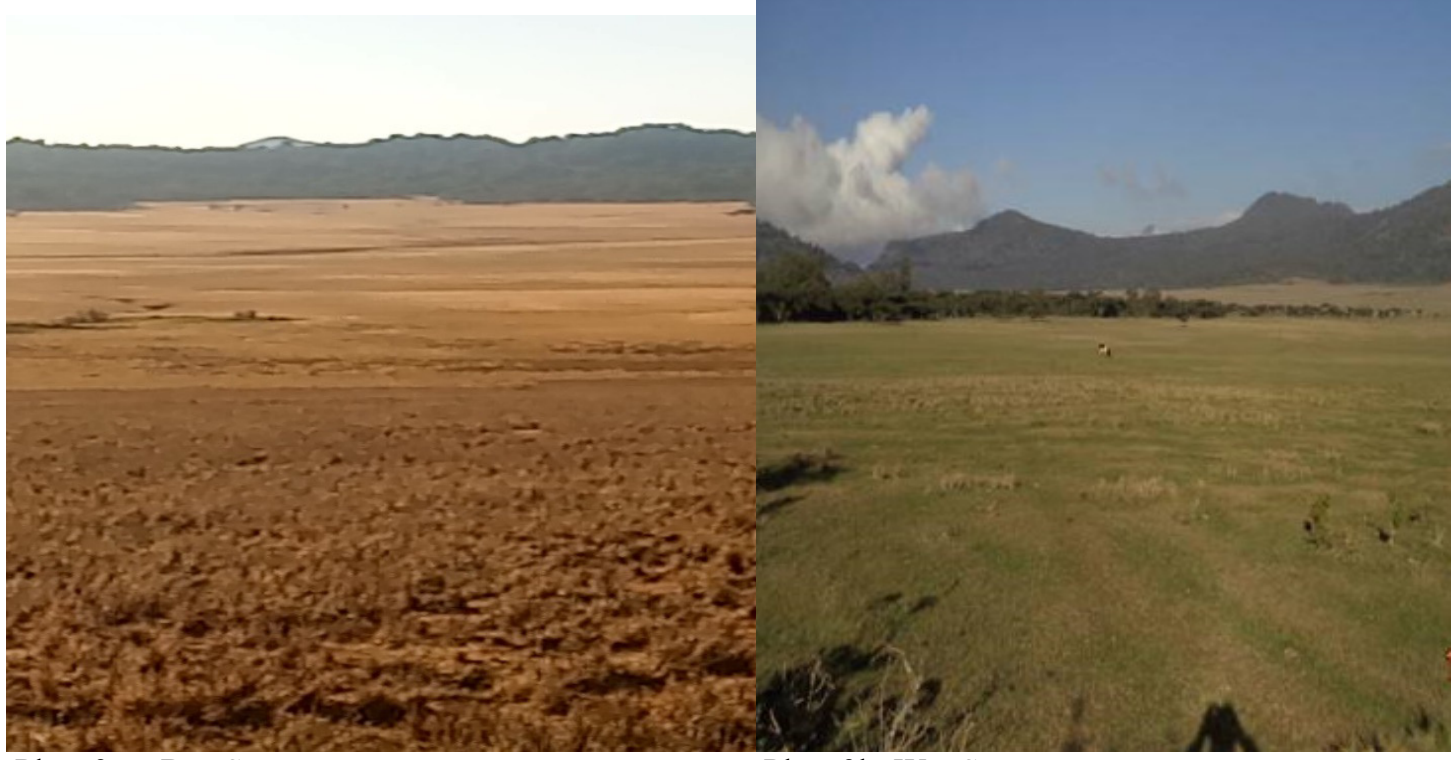

Plate 3a, Dry Season

Plate 3b, Wet Season

Plate 3: Grassland habitat (3a, Dry Season; 3b, Wet Season) (photo: Dadi, 2019).

\subsubsection{Data Collection Techniques}

A total of 18 transect were made on the identified four sample area; montane forest, riverine forest, woodland and seasonal grass-wetland habitat to get information on the population size, demographic composition and to predict habitat preference. Twenty trained people were involved in the research to assist transect walk data collection process. Based on the number of transects, ten patrolling teams with two person at each transect were assigned.

Prior to data collection training was given for the patrolling team on how to operate the GPS receiver, to estimate animal observer distance, age category, sex and data recording on data sheet. The transect lines in each sample zone was fixed to assist the foot counts by making use of standard transect counting methods (NortonGriffiths, 1979). The field survey time was early morning (between 6:00 - 10:00 a.m) and late afternoon (3:006:00 p.m.), when the animals were more active for feeding and maximum observation of the animal was possible. 
During the assessments the number, sex, age category of bushbuck and habitat type and location were recorded. Data collection was made through direct observations with naked eye and/or by using binoculars. As indicated by Wilson et al. (1996), the direct observational technique is most appropriate for medium to large sized animals. Further, silent detection method like traveling against direction of wind was also applied to minimize disturbances (Wilson et al., 1996). Indirect evidences such as fresh fecal droppings, feeding marks were used to confirm doubtful observations of the animals. Furthermore, stopping after every $50 \mathrm{~m}$ for about a minute were followed to listen for animals or branch movements and vocalizations, to maximize the counting.

To increase the accuracy of estimation of the populations, each transect was repeated three time both during the wet and dry seasons (Buckland, 2001). Repeated counting of the same herd or cluster were avoided using recognizable features; such as group size, and group composition (Wilson et al., 1996). Each individual sex and age classes were identified and categorized following Befekadu Refera and Afework Bekele (2004) and Dereje Yazezew et al. (2011).

Binoculars were used for proper sex and age identification. Age and sex determination were carried out based on body size, presence or absence of horn, horn size and coat color. The individual or individuals in a herd were recorded as adult male (AM), adult female (AF), sub-adult male (SAM), sub-adult female (SAF) and young of both sex (Kingdom, 1997). Sex ratios for the animals obtained from direct count of the animals using the methods of Hillman (1986).

\subsubsection{Data analysis}

Data was analyzed using SPSS version 20 computer software program. Animals counted during different seasons, sex, age category, wet and dry season population estimation and habitat preference, were compared by chisquare test. Descriptive statistical presentations such as percentages mean and frequency distribution tables also used. In addition for density estimation, the method of Sutherland (1996), Density: D = N/2LW, where D = estimated density of animal, $\mathrm{N}=$ number of animal seen, $\mathrm{L}=$ length of transect lines and $\mathrm{W}=$ mean perpendicular distance of animals seen was applied.

\subsection{LIMITATIONS OF THE STUDY}

The difficult terrain of the controlled hunting area (high and rugged mountainous ridges with high slopes and gently rolling steep hills) together with height of the vegetation growth and thick cover has made the transect walk challenging to cover long transect distances during the study and the census activities difficult that might limit sighting of bushbuck in the controlled hunting area. Nevertheless, in order to attain the objective of the study, the required information was satisfactorily collected from the area regardless of the challenges.

\section{RESULT}

\subsection{Population Size Estimation of Menelik's Bushbuck}

The field assessment result of Menelik's bushbuck population shows high number of Menelik's bushbuck in the montane forest area and low in the seasonal grass-wetland (Rare) area. The bushbuck population for wet and dry seasons in the study area is given in Table 2. On average, 34 and 47 individuals of Menelik's bushbuck were recorded during the wet and dry seasons respectively. The average numbers of individuals observed for both seasons of the study were 40.5. The population estimate for the CHA was 519.36 individuals. There were no significant difference in the number of animals observed during wet and dry seasons $\left(\chi^{2}=2.09\right.$, df $\left.=1, \mathrm{P}>0.05\right)$. Yet, there was improved count during the dry season.

Table 2: Population Size Estimation of Menelik's Bushbuck (Mean $\pm \mathrm{SE}$ )

\begin{tabular}{lllllll}
\hline \multirow{2}{*}{$\begin{array}{l}\text { Types } \\
\text { Animal }\end{array}$} & of & Seasons & \multicolumn{5}{c}{ Habitat Types } \\
\cline { 3 - 7 } Menelik & & M/Forest & Wood L & Riverine F & S/grass-w & Total \\
bushbuck & Wet & 23 & 6 & 2 & 3 & 34 \\
& Dry & 29 & 4 & 6 & 8 & 47 \\
& Mean & $26 \pm 5.9$ & $5 \pm 1$ & $4 \pm 1.4$ & $5.5 \pm 2.5$ & $40.5 \pm 5.5$ \\
& Density & $2.6 \pm 0.6$ & $1.56 \pm 0.7$ & $3.33 \pm 3.2$ & $1.52 \pm 1.4$ & $2.25 \pm 0.44$ \\
\cline { 2 - 7 } & P/Estimate & 414.99 & 45.97 & 48.95 & 9.45 & 519.36 \\
\hline
\end{tabular}

$\mathrm{M} /$ Forest $=$ Montane Forest, Wood $\mathrm{L}=$ Woodland, Grass $\mathrm{L}=$ Grassland, Riverine $\mathrm{F}=$ Riverine forest, $\mathrm{S} / \mathrm{grass}-\mathrm{W}=$ Seasonal grass-wetland (locally known as Rare),P/ Estimates= Population Estimates

\subsection{Age Structure}

The proportion of age categories of Menelik's bushbuck in the study area is indicated in Table 3. Out of a total number of 81 individuals observed Menelik's bushbuck; 45(55.5\%) were adult, among these $18(22.2 \%)$ were adult male, and $27(33.3 \%)$ were adult females. Similarly from the observed total population, $27(33.3 \%)$ were sub-adult, with the composition of $13(16.1 \%)$ were sub-adult male and $14(17.3 \%)$ were sub-adult female. However the portions of young's were only $9(11.1 \%)$. For all age categories, there were no significant differences between wet and dry season count $\left(\chi^{2}=1.8, \mathrm{df}=1, \mathrm{p}>0.05, \chi^{2}=0.04, \mathrm{df}=1, \mathrm{p}>0.05, \chi^{2}=1\right.$, df $=1$, 
$\mathrm{p}>0.05$ ) respectively for adult, sub-adult and young.

Similarly, the age ratios of adult bushbuck to sub-adult is statistically not significant $\left(\chi^{2}=2.25, \mathrm{df}=1, \mathrm{p}>\right.$ $0.05)$. However, the mean ratio of adult to young was statistically significant $\left(\chi^{2}=12, \mathrm{df}=1, \mathrm{p}<0.05\right)$.

Table3: Age structure

\begin{tabular}{llllll}
\hline Age category & \multicolumn{2}{c}{ Seasons } & Total & Mean & Percent (\%) \\
& Wet & Dry & & & 22.2 \\
\hline Adult M & 7 & 11 & 18 & 9 & 33.3 \\
Adult F & 11 & 16 & 27 & 13.5 & 55.5 \\
Adult M+F & 18 & 27 & 45 & 22.5 & 16.1 \\
SAM & 6 & 7 & 13 & 6.5 & 17.3 \\
SAF & 7 & 7 & 14 & 7 & 33.3 \\
SAM+SAF & 13 & 14 & 27 & 13.5 & 11.1 \\
Young & 3 & 6 & 9 & 4.5 & 100 \\
\hline Total & 34 & 47 & 81 & 40.5 & \\
\hline
\end{tabular}

Where: Adult $\mathrm{M}=$ Adult Male, Adult $\mathrm{F}=$ Adult Female, $\mathrm{SAM}=$ Sub-Adult Male, $\mathrm{SAF}=$ Sub-Adult Female,

\subsection{Sex ratio}

As indicated on (Table 4), from the total observation41 (50.62\%) individuals were females (both adult and subadult) while $31(38.27 \%$ ) were males (both adult and sub-adult). During the study unequal sex ratio was observed in the population. The observed ratio of male to female was 1:1.32, the ratio of adult to all age was $1.25: 1$, while young age to all was $1: 80$ and young to female was 1:4.56. Based on the observed result, the male bushbuck to female sex ratio was statistically not significant $\left(\chi^{2}=0.43, \mathrm{df}=1, \mathrm{p}>0.05\right)$.

Table 4: Age and sex ratio of Menelik's bushbuck in wet and dry seasons

\begin{tabular}{lllllll}
\hline & & \multicolumn{5}{c}{ Ratio } \\
\cline { 3 - 6 } Type of Animal & Season & Male:Female & Adult: All & Young: All & Young: S/Adult & Young: Female \\
\hline Menelik's bushbuck & Wet & $1: 1.38$ & $1.13: 1$ & $1: 10.33$ & $1: 4.33$ & $1: 6.00$ \\
& Dry & $1: 1.28$ & $1.35: 1$ & $1: 6.83$ & $1: 2.33$ & $1: 3.83$ \\
& Mean & $1: 1.32$ & $1.25: 1$ & $1: 80$ & $1: 3.00$ & $1: 4.56$ \\
\hline
\end{tabular}

\subsection{Grouping Patterns of the Animal}

During the study period the composition of social groups (clusters) observed for Menelik's bushbuck were groups composed of all females group, all males, male and female groups, females and young groups, and mixed groups of both sexes and young. Throughout the study period, the most commonly observed groups were groups containing solitary bushbuck. The highest range of group size was recorded during the dry season (1-4 individuals), mean group size and the total number of groups observed during the dry season was 1.52 and 31 , respectively. However, during the wet season the mean group sizes recorded and the total numbers of groups observed were 1.21 and 28 , respectively (Table 5). There was no significant difference in the mean group size $\left(\chi^{2}\right.$ $=0.04, \mathrm{df}=1, \mathrm{p}>0.05$ ) counted during the dry and wet seasons (Table 5).

Table 5: Social group size of Menelik's bushbuck

\begin{tabular}{llllll}
\hline Animal Type & Season & Individuals observed & Number of groups & Group range & Mean group size \\
\hline Menelik's Bushbuck & Wet & 34 & 28 & $1-3$ & 1.21 \\
& Dry & 47 & 31 & $1-4$ & 1.52 \\
\cline { 2 - 6 } & Mean & 40.5 & 29.5 & $1-3.5$ & 1.37 \\
\hline
\end{tabular}

\subsection{Habitat Utilization of Menelik's Bushbuck}

During the study period, the number of individual bushbuck observed in each habitat type is given in Table 6 . Menelik's bushbuck showed more preference for montane forest both during wet and dry seasons. Out of 81individuals observed during wet and dry seasons, 23(67.6\%) individuals in wet season and 29(61.7\%) individuals in dry season were observed in montane forest habitat type. There were no significant difference in use of this habitat in both seasons $\left(\chi^{2}=0.69, \mathrm{df}=1, \mathrm{P}>0.05\right)$. In addition, on average during both seasons Menelik's bushbuck showed habitat preferences of $13.6,12.3 \%$ and $9.9 \%$ for seasonal grass-wetland habitat, woodland and riverine forest habitats respectively. However, there is significant difference in habitat use of Menelik's bushbuck $\left(\chi^{2}=33.29, \mathrm{df}=3, \mathrm{p}<0.05\right)$ among the four habitat types. 
Table 6: Habitat utilization of Menelik's Bushbuck

\begin{tabular}{lllll}
\hline Habitat Type & Seasons & & & Motal \\
\cline { 2 - 5 } & Wet & Dry & $26(64.2)$ & 52 \\
\hline Montane Forest & $23(67.6)$ & $29(61.7)$ & $5(12.3)$ & 10 \\
Woodland & $6(17.6)$ & $4(8.5)$ & $4(9.9)$ & 8 \\
Riverine Forest & $2(6.0)$ & $6(12.8)$ & $5.5(13.6)$ & 11 \\
Seasonal grass-wetland & $3(8.8)$ & $8(17.0)$ & $40.5(50.0)$ & 81 \\
\hline Total & $34(42.0)$ & $47(58.0)$ & & \\
\hline
\end{tabular}

\section{DISCUSSION}

Even though Menelik's bushbucks are endemic to Ethiopia, little is known about the population status, habitat use and other related ecological features of Menelik's bushbuck in Ethiopia. Even though only few studies were carried out in different protected areas of the country, still no scientific study was carried out in AbashebaDemero CHA.

For proper conservation of the population of endemic Menelik's bushbuck in the CHA and to set quota on the number of adult male bushbuck to be hunted per year; estimating the population size and describing their habitat utilization and distribution in the study area is very important and different characteristics of this animal were compared with the studies conducted in Ethiopia by Dereje Yazezew et al. (2011) in Borena Sayint National Park, Abebayehu Dessalagn and Tilaye Wube (2012) in the Menagesha-Suba State Forest, Mignot Zerihun (2012) in Bale Mountain National Park, Mustefa Sultan et al. (2017) in Munessa Kukke Controlled Hunting Area and Dejene Worku and Demeke Datiko (2018) in Hanto Controlled Hunting Area, as well as other studies elsewhere.

During the study period there was no significant difference in number of bushbuck in both seasons. Yet, more Menelik's bushbucks $(58.0 \%)$ were counted in the dry seasons than wet season. The most rational reason for this might be due to human activities such as collection of firewood and livestock encroachment were very high in the CHA during the wet season as agricultural lands are cultivated in wet season. This might reduce the sighting probability of the Menelik's bushbuck, which.

Cultivation at lower altitudes during the wet season leads to the displacement of livestock into the high altitudes. However, during the dry season, after crops were harvested, livestock and pack animals move to lower altitude towards agricultural lands to feed on crop residues. Seasonal difference in the abundance of livestock grazing was also observed by Zerihun Girma et al. (2012) in Mount Kaka and Hunkolo Fragments. Studies in different places have also revealed the adverse effect of livestock encroachment and human settlement on the abundance and distribution of wild animals (Stephens et al., 2001; Zerihun Girma et al., 20012; Dejene Worku and Demeke Datiko, 2018). On the other hand, the foggy weather condition and availability of resources near their home range during wet season might reduce the counting of bushbuck in wet season.

The findings of Kie (1988) recommended to measure and estimate the population density of a given species to detect the enactment of wild animals including the condition and health of the population changing aspects. Based on the current results, the mean estimated density of the population for the CHA was $2.25 \mathrm{~km}^{2}$, however in riverine forest habitat the density was high $\left(3.33 \mathrm{~km}^{2}\right.$ compared to other habitats and minimum $\left(1.52 \mathrm{~km}^{2}\right)$ in seasonal grass-wetland (Rare) habitat. The data obtained in the present study is comparable to that of Mustefa Sultan et al. (2017) in Munessa Kukke Controlled Hunting Area, Oromia Regional State, Ethiopia for the same species; the authors have reported a density of $2.575 \mathrm{~km}^{2}$.

However the present result is different from the findings of Dereje Yazezew et al. (2011) in the Denkoro Forest National Park; Abebayehu Dessalagn and Tilaye Wube (2012) in the Menagesha-Suba State Forest, Mignot Zerihun (2012) in Bale Mountain National Park (Gaysay-Adelay area), and Dejene Worku and Demeke Datiko (2018) in Hanto Controlled hunting area; these studies reported the density of Menelik's bushbuck to be $11.75 \mathrm{~km}^{2}, 12 \mathrm{~km}^{2}, 11.52 \mathrm{~km}^{2}, 4 \mathrm{~km}^{2}$ respectively.

It is difficult to evaluate the long term population trend of Menelik's bushbuck in Abasheba-Demero CHA, as periodic censuses have not been conducted in the CHA and this study was the initial for the place. However, information's collected from local people, EWCA and CHA scouts indicated that, the population of wildlife's are increasing after the establishment of the CHA. The reduced illegal hunting might be, because of high penalty. Study conducted by Dejene Worku and Demeke Datiko (2018) in the areas with similar conservation status (Hanto Controlled Hunting Area) has noted similar reasons with this finding.

The observation of sex ratio and age structure of individual animal is vital for evaluating the sustainability of a species for the reason that, these variables reflect the structure and the dynamics of population (Wilson et al., 1996). Sex and age structure of a population at any given point of time is also an indicator of the status of the population. The present study revealed that male to female sex ratio (1:1.32) was unequal and biased towards females. Therefore, relatively the higher population number of females in the CHA is beneficial in relation increasing new individuals of the population through birth. Therefore the current observation indicates a healthy 
Menelik's bushbuck population in the CHA area.

Related findings were also obtained both by Mignot Zerihun (2012 and Dejene Worku and Demeke Datiko (2018). The possible reason for unequal sex ratio might be because of male-biased selective sport hunting practices in the study area. As the area is established for trophy hunting, up to six adult male bushbucks per year have been hunted by professional hunters. In addition, for lower number of males in the CHA could be due to probability of increase in killing of males Menelik's bushbucks due to predation.

The males leave the birth herd and distributed in less favorable habitats, and suffer an increased predation pressure compared with the females of the same age classes, which stay in the natal herd (Apio et al., 2010). Wronski (2004) also confirmed that, the young female ungulates maintain their relationship with their mother group for some time after weaning. Young males, however, may soon become displaced because of antagonistic behavior from other males.

The identified young to female ratio was 1:4.56, which shows young productivity was 0.22 young per adult females (22 young per 100 adult females). Productivity of young observed in this study was related with that of Abebayehu Dessalagn and Tilaye Wube (2012) in the Menagesha-Suba State Forest. On the other hand, the high proportion of adults in the present study could indicate higher degree of survival of sub-adults.

The low proportion of young to other age groups, $(1: 80)$ was observed during the investigation. This might be the young ones are more vulnerable to predators and hidden under dense grasses and vegetation. This was in line with the findings of Wronski (2004), Dereje Yazezew et al. (2011), Mignot Zerihun (2012 and Dejene Worku and Demeke Datiko (2018) which confirmed that at the early stage of their lives the young are highly vulnerable to predation. On the other hand, low proportion of sub-adults to others in the present investigation shows a problem of long term survival of the young in the area. The most plausible reason was due to the existence of a number of predators such as common jackal, domestic dog, spotted hyena, baboon and leopard in the CHA.

During the study the groups observed were social group's composed different age and sex categories. The result shows that there is no significant difference between wet and dry seasons in forming group numbers A group of all males, all females, male and female group, females and young group, and mixed groups of both sexes and young were observed. The most commonly observed group sizes throughout the study period were single or solitary bushbuck. It confirms the findings at other different places that describe; bushbucks are solitary animals which exhibit momentary male-to-female pairing during the breeding season (Alden et al., 2000; Coates and Downs, 2007; Wronski et al., 2009; Abebayehu Dessalagn and Tilaye Wube, 2012). However, the present finding is not in line with the suggestion of Kingdon (1997) who stated that bushbucks are strictly solitary.

Habitat utilization and distribution of the animals depend on the availability of shelter, food and water. The distribution of Menelik's bushbuck in different habitats (montane forest habitat, woodland, riverine forest and seasonal grass-wetland habitat) shows significant seasonal variation. This shows that there is differences in vegetation change and forage quality in the area from season to season. The study result for the habitat utilization shows that Menelik's bushbuck was more abundant in dense vegetation of riverine and montane forest. Specifically with respect to habitat utilization, high frequency was observed for the montane forests (3.33individual per $\mathrm{km}^{2}$ ) and lower (1.52 individual per $\mathrm{km}^{2}$ ) for seasonal grass-wetland. This might be because the bushbucks use the dense forest not only as source of food but also as cover from strong sun light and predation

Though, Menelik's bushbuck was evenly distributed in the four dominant habitats, they showed high preference for montane and riverine forest and least distributed in seasonal grass-wet habitat. This might be because of cryptic and shy nature of bushbucks. So to hide themselves from predators and human disturbances, bushbucks preferred areas with dense vegetation cover and availability of resources. Moreover, habitat selection may be influenced by vegetation type, the presence of water, topographical features, predator avoidance and availability of food and other environmental factors among habitats and between seasons within each habitat. This observation is in line with the findings of Kingdon (1997); Wronski et al. (2008); Hailemariam et al. (2015) and Zerihun Girma et al. (20015) for the same species in different places, that states; most of bushbucks are forest living animals inhabiting dense bush.

\section{CONCLUSION}

Menelik's bushbucks are endemic subspecies to Ethiopia. However, little is known about the population status, habitat use and other related ecological features of Menelik's bushbuck in Ethiopia. Even though only few studies were carried out in different protected areas of the country on the present study animal, yet no scientific study was conducted in Abasheba-Demero CHA. Therefore, the present investigation provides valuable information on population size, population structure, habitat use, and social grouping patterns of Menelik's bushbuck in the study area.

Accordingly, the study shown that, enormous numbers of Menelik's bushbuck exist in Abasheba-Demero CHA. The population structure indicated a healthy population dynamics of the specie in the area (i.e. the 
population was not in immediate danger). Conversely, as the study site is hunting concession, it needs continuous monitoring of population status and related ecological problems in the area. During filed survey a number of conservation challenges have been observed; among them as the CHA is semi protected (i.e. Local people allowed to access resources like grazing without restriction, fuel wood collection, getting trees for constriction) and illegal human and livestock encroachment to the wildlife habitat. The findings could serve as a baseline to make comparison against future research findings, also will help to set annual quota for trophy hunting and improve wildlife conservation and management decisions in the CHA.

Therefore, the following recommendations were made for the feasible management and utilization of wildlife resources by mitigating conservation threats and maximizing the benefits of local people:- Since, Menelik's bushbucks and mountain nyala are frequently hunted for trophy in the area, continuous studies should be conducted further on the ecology, reproductive patterns and population dynamics of the animal, The CHA management (Ethiopian Rift Valley Hunting Safari Privet Limited Company) should have good communication with the local community and need to recruit scouts to control illegal activities in the CHA, The regional and federal governments need to improve the living standards of the local people to reduce their dependence on the CHA.

\section{Acknowledgements}

The authors would like to thank Ethiopian Rift Valley Safaris PLC for their support during data collection and logistics, Ethiopian Wildlife Conservation Authority, Oromia forest and wildlife conservation Enter price of Bale branch for their permeation to conduct the research on the CHA.

\section{Conflicts of Interest}

The authors did not declare any conflict of interest.

\section{REFERENCES}

Abebayehu Dessalagn and Tilaye Wube (2012). Population density, structure and grouping pattern of Menelik's bushbuck in the Menagesha-Suba State Forest: Ethiopia. Journal of Science, 35: 129-134.

Apio, A., Kabasa, J., Ketmaier, V., SchrÖder, C., Plath, M. and Tiedemann, R. (2010). Female philopatry and male dispersal in a cryptic, bush-dwelling antelope: Acombined molecular and behavioural approach. Journal of Zoology, 280: 213-220.

Apio, A. and Wronski, T. (2005). Foraging behaviour and diet composition of bushbuck (Tragelaphusscriptus Pallas, 1766) in Queen Elizabeth National Park, western Uganda. African Journal of Ecology 43: 225-232.

Befekadu Refera and Afework Bekele (2004). Population status and structure of mountain nyala in the Bale Mountains National Park: Ethiopia. African Journal of Ecology, 42: 1-7

Buckland, S. (2001).Introduction to Distance Sampling: Estimating Abundance of Biological Populations. Oxford University Press, Oxford.

Buckland, S., Anderson, D., Burnham, K., and Laake, J. (1993). Distance sampling: estimating abundance of biological populations. Chapman and Hall, London.

Coates, G. and Downs, C. (2007). Population estimates of bushbuck (Traglaphusscriptus) in valley thicket and coastal bushveld-grassland habitat. S. African Journal of Wildlife Resource, 37:91-95.

Dejene and Demeke (2018).Population Status, Distribution and Social Grouping Patterns of Menelik's Bushbuck (Tragelaphusscriptusmeneliki) in Hanto Controlled Hunting Area, Ethiopia. Asian Journal of Science and Technology, 09: 8727-8734

Dereje Yazezew, YosefMamo and AfeworkBekele (2011).Population ecology of Menelik'sbushbuck (Traglaphusscriptusmeneliki) from Denkoro Forest Proposed National Park: Northern Ethiopia. International Journal of Ecology and EnvironmentalScience, 37:1-13.

Evangelista P, N Young, D Swift, AWolde(2015).Demographic Observations of Mountain NyalaTragelaphusBuxtoni in a Controlled Hunting Area, Ethiopia.Journal of BiodiversityEndangeredSpecies 3:145

Federal Negarit Gazeta (2009).Wildlife Development, Conservation and Utilization Council of Ministers Regulations No. 163/2008. Addis Ababa, Ethiopia.

Hailemariam, B., Gadisa, T., Habtamu, T. and Gelaye, H. (2015). The status and feeding ecology of Menelik's bushbuck (Tragelaphusscriptusmeneliki, Neumann 1909) in Wof-Washa Forest, North Showa, Ethiopia. International Journal of Current Research, 7: 16366- 16370.

Hillman, J. (1986). Bale Mountains National Park Management Plan.Ethiopian Wildlife Conservation Organization (EWCO), Addis Ababa.

Hobbs, N. (1996). Modification of ecosystems by ungulates. Journal of Wildlife Management,60: 695713.Hunting for sustainability http://fp7hunt.net. Accessed on July 2018

Hofmann, R. (1973). The Ruminant Stomach. East African Lit, Bureau. 
Kie, J. (1988). Performance in Wild Ungulates: Measuring Population Density and Condition of Individuals. Pacific Southwest Forest and Range Experiment Station, Berkeley.

Kingdon, J. (1997). The Kingdon Field Guide to African Mammals: Academic Press. San Diego.

Last, J. (1982). Endemic Mammals of Ethiopia. Ethiopian Tourism Commission, Addis Ababa.

Mekonnin, Z. (2013). Productivity of eucalyptus camaldulensis (Dehnh.) in GoroWeroda of Bale Zone, Ethiopia. Journal of Agriculture and Environmental management. 2: 252-260

Mignot Zerihun (2012. Population Status, Habitat Association, Feeding Behaviour and Diurnal Activity of Menelik's Bushbuck (Tragelaphusscriptusmeneliki) in Dinsho, Bale Mountains National Park, Ethiopia.Masters Thesis, Addis Ababa University,

Moodley, Y. and Bruford, M.W. (2007). Molecular biogeography: towards an integrated Frame work for conserving pan-African biodiversity. PLoS One 5: 1-9.

Moodley, Y., Bruford, M.W., Bleidorn, C., Wronski, T., Apio, A. and Plath, M. (2008).

Analysis of mitochondrial DNA data reveals non-monophyly in the bushbuck (Tragelaphus scriptus) complex. Mamm. Biol. 74: 418-422.

Mustefa Sultan, Teyiba Amano and Aklilukebede (2017). Quota Setting for Sustainable Utilization Game Animals for Sport Hunting in Ethiopia: The Case of Munessa Kukke Controlled Hunting Area, Oromia Regional State, Ethiopia. Advances in Life Science and Technology;54:35-44

Norton-Griffiths, M. (1979).Counting Animals.East African Wildlife Foundation. Nairobi.

Stephens, P., Candy, A., Sillero-Zubiri, C. and Leader-Williams, N. (2001). Impact of livestock and settlement on the large mammalian wildlife of Bale MountainsNational Park: Southern Ethiopia. Biological Conservation, 100: 307-322.

Sutherland, J. (1996). Ecological Census Technique, Hand Book. Cambridge University Press, Cambridge.

Wilson, D., Cole, F., Nichols, J., Rudran, R. and Foster, M. (1996). Measuring and Monitoring Biological Diversity. Standard Methods for Mammals.Smithsonian Institution Press, Washington, DC.

Wronski, T. (2004).The Social and Spatial Organization of Bushbuck (Tragelaphusscriptus Pallas 1776) in Queen Elizabeth National Park, Uganda.Ph.D.thesis. University of Hamburg.

Wronski, T., Apio, A., Baranga, J and Plath, M. (2006). Scent marking and territorial defense in male bushbuck (Tragelaphusscriptus). Journal of Zoology, 270: 49-56.

Wroniski, T., Kabasa, J., Apio, A. and Plath, M. (2008). Object- horning as advertising and marking behavior in male bushbuck (Traglelaphusscriptus). Ethology, 26: 165-176.

Wronski, T., Apio, A., Plath, M. and Averbeck, C. (2009). Do ecotypes of bushbucks differ in grouping patterns? Acta Ethologica, 12: 71-78.

Yalden, D., Largen, M. and Kock, D. (1984).Catalogue of the mammals of Ethiopia. Artiodactyla.Monitoring Zoology, 19: 67-221.

Zerihun Girma, AfeworkBekele and Hemson Graham (2012).Large Mammals and Mountain Encroachments on Mount Kaka and Hunkolo Fragments, Southeast Ethiopia.Asian Journal of Applied Sciences, 5: 279-289.

Zerihun Girma, George Chuyong, Paul Evangelista and Yosef Mamo( 2015). "Habitat characterization and preferences of the mountain nyala (Tragelaphusbuxtoni, Lydekker 1910) and menelik's bushbuck (Tragelaphusscriptusmeneliki, Neumann 1902) in Arsi mountains national park, south-eastern Ethiopia”, International Journal of Current Research, 7: 23074-23082. 